\title{
Keratosis follicularis-dwarfism-cerebral atrophy syndrome
}

INSERM

\section{Source}

INSERM. (1999). Orphanet: an online rare disease and orphan drug data base. Keratosis follicularis-dwarfism-cerebral atrophy syndrome. ORPHA:2339

Keratosis follicularis-dwarfism-cerebral atrophy syndrome is characterized by generalized keratosis follicularis, severe proportionate dwarfism and cerebral atrophy. It has been described in six males from one family (three boys and three maternal uncles).

Generalized alopecia and microcephaly were also present. 